\title{
Properties of Recycled High Density Polyethylene (RHDPE)/ Ethylene Vinyl Acetate (EVA) Blends: The Effect of Blends Composition and Compatibilisers
}

\author{
Fatimah Abd Rajak Hamim, ${ }^{1}$ Supri Abdul Ghani ${ }^{2 *}$ and Firuz Zainudin ${ }^{1}$ \\ ${ }^{1}$ School of Materials Engineering, Universiti Malaysia Perlis (UniMAP), \\ Kompleks Taman Muhibah, Jejawi 2, 02600 Arau, Perlis, Malaysia \\ ${ }^{2}$ Faculty of Engineering Technology, Universiti Malaysia Perlis (UniMAP), \\ Main Campus, Pauh Putra, 02600 Arau, Perlis, Malaysia \\ *Corresponding author: supri@unimap.edu.my
}

Published online: 25 August 2016

To cite this article: Hamim, F. A. R, Abdul Ghani, S. \& Zainudin, F. (2016). Properties of recycled high density polyethylene (RHDPE)/ethylene vinyl acetate (EVA) blends: The effect of blends composition and compatibilisers. J. Phys. Sci., 27(2), 23-39, DOI: 10.21315/jps2016.27.2.3

To link to this article: http://dx.doi.org/10.21315/jps2016.27.2.3

\begin{abstract}
Recycled high density polyethylene (RHDPE)/ethylene vinyl acetate (EVA) blends with different blend compositions and compatibilisers were prepared by using melt blending technique in Brabender Plasticorder at temperature $160^{\circ} \mathrm{C}$ and rotor speed of $50 \mathrm{rpm}$ for $10 \mathrm{~min}$. The compatibilisation of RHDPE/EVA blends were enhanced by the addition of $6 \mathrm{phr}$ of polyethylene-grafted-maleic anhydride (PE-g-MAH) and caprolactam-maleic anhydride (CL-MAH) as compatibilisers. The tensile properties, swelling behaviour, morphology and infrared spectroscopy analysis were studied. The tensile properties and morphology analysis showed that RHDPE/EVA blends became softer with the increasing EVA content. The results also revealed that there was good compatibility between RHDPE/EVA blends with addition of PE-g-MAH and CL-MAH lead to improvement in tensile properties and swelling behaviour of the blends compared to RHDPE/EVA blends without the presence of compatibilisers. SEM morphology displayed better interfacial adhesion due to good dispersion and interaction between RHDPE and EVA phases into each other caused by the compatibilisation effect of PE-g$M A H$ and CL-MAH. Fourier transformed infrared spectroscopy (FTIR) revealed the structure of the polymer blend with the addition of CL-MAH and PE-g-MAH as compatibilisers.
\end{abstract}

Keywords: Polymer blends, recycled high density polyethylene, ethylene vinyl acetate, hybrid compatibiliser, polyethylene-grafted-maleic anhydride, caprolactam-maleic anhydride 


\section{INTRODUCTION}

In recent years, polymer blending has been acknowledged as an efficient method to achieve cost and performance balance for both the industrial and scientific communities. Polymer blends can be defined as physical mixtures of structurally different polymers with no covalent bonds taking place between them. These different polymers adhere together through the action of secondary bond forces only. ${ }^{1}$ There is a lot of interest in polymer blends mainly due to two reasons. First is the challenge in producing new kind of polymeric materials from monomers, and second, polymer blending can be achieved at a more effective cost. ${ }^{2}$ However, most blends of different polymers lead to presence of coarse phase morphologies, resulting in poor ultimate properties. Unfavourable interactions of the polymers result in high interfacial tension and make the melt-mixing of the two components challenging. The limited miscibility between the polymers is due to the large size of the polymer chains which caused high interfacial tension and poor adhesion between the segregated phases. These segregated phases act as a barrier to an effective stress transfer between the phases, and uneven morphology shows poor adhesion between the phases leading to the poor mechanical properties of the final blends. ${ }^{3,4}$

Compatibilisation of an immiscible polymer blend can be done by altering the interfacial properties which can result in the formation of the interphase and stabilise the blend morphology. The uniform blend can be attained with the help of compatibiliser, an additive which added in polymer blends to improve the adhesion and interaction between two components of polymer. ${ }^{5}$ The incorporation of a surface-active species called compatibiliser, which deliberates at the interface can lead to improvement in interfacial adhesion and stabilisation of the blend morphology. ${ }^{6}$ A compatibiliser acts as a dispersant that lowers the characteristic size of the heterogeneous morphology, significantly improves adhesion between the continuous and dispersed phase in the blend, and reduces the interfacial tension. These consequently result in suppression of coalescence in the dispersed phase. ${ }^{7}$ Compatibiliser can be found in many forms such as copolymer which can be added to the blend, or generated in-situ during the blending process by a chemical reaction for reactive compatibilisation, forming covalent bonding directly at the interface. ${ }^{8}$ The most reactive compatibilising agents which had been investigated included precursors containing anhydride, carboxylic acid, and epoxide groups. The highly reactive maleic anhydride (MAH) has been widely used in reactive compatibilisation. ${ }^{9}$ Zhang et al. ${ }^{10}$ presented a very elaborate and broad review on the reported work on the usage of maleic anhydride-grafted poly(styrene-ethylene/butyl-diene-styrene) (SEBS-g$\mathrm{MAH})$ as compatibiliser on blend of recycled poly(ethylene terephthalate) (RPET) and linear low density polyethylene (LLDPE). They found that from the 
mechanical properties, the tensile properties, elongation at break, and charpy impact strength increased with increasing content of SEBS-g-MAH compared to poly(styrene-ethylene/butyl-diene-styrene) (SEBS) as compatibiliser.

Plastic recycling has become one of the methods for reducing environmental impact, resource consumption, and pollution. Recycling can lessen energy and material usage per unit of production and therefore improved eco-efficiency. As for the importance of recycling, the use of recycled high density polyethylene (RHDPE) is a reality at the present time, therefore a better understanding of the behaviour of RHDPE is necessary. ${ }^{11,12}$ HDPE is a thermoplastic material exhibiting excellent mechanical properties, great ozone resistance, superior chemical resistance, and good electrical properties. ${ }^{13}$ Ethylene vinyl acetate (EVA) is the copolymer of ethylene and vinyl acetate parts formed via free radical polymerisation with properties of high impact strength, good aging resistance, high moisture absorption, low tensile strength, and better corrosion protection. ${ }^{14}$ Chen et al. ${ }^{13}$ reported the melting and crystallisation behaviour of partially miscible high density polyethylene/ethylene vinyl acetate copolymer (HDPE/EVA) blends. All those results from differential scanning calorimetry (DSC) and wide angle X-ray scattering (WAXS) testing indicate that the polymer pair was partially miscible. Takidis et al. ${ }^{15}$ investigated the compatibility of $\mathrm{PE} / \mathrm{EVA}$ blends and stated that the blend composition and process temperature play essential roles in determination of the compatibility. They proposed that mixing temperature must be higher than $180^{\circ} \mathrm{C}$ for attaining improvement in mechanical properties. Bing et al. ${ }^{16}$ reported that molecular orientation and interfacial interaction become very significant to conclude the tensile behaviour and fracture toughness for HDPE/EVA blends. They evaluated that high impact strength increased while low impact strength decreased with increasing content of EVA.

Although a considerable number of research works have been done on PE/EVA and HDPE/EVA blends, there is a little work in the use of recycled HDPE as one of the main compounds in RHDPE/EVA blends, and the relationship between mechanical, physical, and morphology of these blends. Besides, the use of hybrid compatibiliser of CL-MAH can be considered as new research in the field of polymer blends. The main objective of the present work was to study the tensile properties and morphology of different blend ratios of RHDPE/EVA blends and their relationships, with and without the presence of compatibilisers. To this end, the influence of the above mentioned compatibilisers on the properties of RHDPE/EVA blends were scientifically investigated. Additionally, the diagram of interaction between RHDPE/EVA blends and the compatibiliser would also be proposed by referring to the data from FTIR analysis. 


\section{EXPERIMENTAL}

\subsection{Materials}

RHDPE with melt flow index of $0.7 \mathrm{~g} 10 \mathrm{~min}^{-1}\left(190^{\circ} \mathrm{C}\right)$ and density of $0.941 \mathrm{~g}$ $\mathrm{cm}^{-3}$ was used. EVA containing $18.1 \mathrm{wt} \% \mathrm{VA}$, with melt index of $2.5 \mathrm{~g} 10 \mathrm{~min}^{-1}$ $\left(80^{\circ} \mathrm{C}, 2.16 \mathrm{~kg}\right)$ and density of $0.93 \mathrm{~g} \mathrm{~cm}^{-3}$ was supplied from A. R. Alatan Sdn. Bhd., Kedah, Malaysia. Maleic anhydride with molecular weight of $98.06 \mathrm{~g} \mathrm{~mol}^{-1}$ was supplied by Zarm Scientific \& Supplier Sdn. Bhd., Penang, Malaysia. Caprolactam with molecular weight of $113.16 \mathrm{~g} \mathrm{~mol}^{-1}$, polyethylene-graftedmaleic anhydride containing $0.85 \mathrm{wt} \%$ of maleic anhydride and dibenzoyl peroxide (DBP) with $75 \%$ of water were also obtained from A. R. Alatan Sdn. Bhd.

\subsection{Blend Preparation}

The compounding of the blends was carried out by melt blending in Brabender internal mixer. The RHDPE was first mixed in the internal mixer at $160^{\circ} \mathrm{C}$ with speed $50 \mathrm{rpm}$ for $2 \mathrm{~min}$, followed by addition of EVA and mixed until homogenous. The compatibiliser, CL-MAH and PE-g-MAH, and DBP were added to the mixer for the remaining 4 min. Next, the softened RHDPE/EVA, RHDPE/EVA/PE-g-MAH, and RHDPE/EVA/CL-MAH blends were removed from the chamber and pressed into thick, round pieces of compounding. Table 1 shows the formulations used in this study.

Table1: Formulation of RHDPE/EVA, RHDPE/EVA/CL-MAH, and RHDPE/ EVA/PEg-MAH blends at different blend compositions.

\begin{tabular}{lccc}
\hline Composites & $\begin{array}{c}\text { RHDPE/EVA } \\
(\mathrm{phr})\end{array}$ & $\begin{array}{c}\text { CL-MAH } \\
(\mathrm{phr})\end{array}$ & $\begin{array}{c}\text { PE-g-MAH } \\
\text { (phr) }\end{array}$ \\
\hline RHDPE/EVA & $80 / 20,60 / 40,40 / 60,20 / 80$ & - & - \\
RHDPE/EVA/CL-MAH & $80 / 20,60 / 40,40 / 60,20 / 80$ & 6 & - \\
RHDPE/EVA/PE-g-MAH & $80 / 20,60 / 40,40 / 60,20 / 80$ & - & 6 \\
\hline
\end{tabular}

\subsection{Compression Molding}

In order to produce the blends in plate form, the hydraulic hot press was used. The machine was set at temperature of $160^{\circ} \mathrm{C}$ both at top and bottom platen. Empty mould was heated for $5 \mathrm{~min}$ before used. Then blends were put into the mould, preheated and compressed partially for $8 \mathrm{~min}$. Once the blends started to soften, they were fully compressed for $6 \mathrm{~min}$. After compression, the blends were allowed to cool for another $4 \mathrm{~min}$. 


\section{$2.4 \quad$ Tensile Testing}

Tensile properties were determined according to ASTM D-638 by using the Universal Testing Machine Instron 5569 with crosshead speed of $30 \mathrm{~mm} \mathrm{~min}{ }^{-1}$. Dumbbell shaped specimens were conditioned at ambient temperature $(25 \pm 3)^{\circ} \mathrm{C}$ and relative humidity $(30 \pm 2) \%$ before the testing. An average of ten samples was used for each formulation. The tensile strength, elongation at break, and Young's modulus of each formulation were obtained from the test.

\subsection{Swelling Behaviour Testing}

The swelling behaviour test was carried out in general accordance with ISO 1817 . Samples with dimension of $20 \mathrm{~mm} \times 10 \mathrm{~mm} \times 2 \mathrm{~mm}$ were used for each blend compositions. The samples were totally immersed into test tubes containing dichloromethane for $46 \mathrm{~h}$. After immersion period, the samples were removed from dichloromethane and blotted with tissue paper before weighed by using an analytical balance with $0.1 \mathrm{mg}$ resolution. The degree of swelling (weight increase) was calculated as follows:

$$
\text { (\%) Mass swell }=\frac{\left(W_{s}-W_{0}\right)}{W_{0}} \times 100
$$

where $\mathrm{W}_{\mathrm{o}}$ is the initial weight of sample, and $\mathrm{W}_{\mathrm{s}}$ the weight of the swollen sample after immersion.

\subsection{Scanning Electron Microscopy (SEM)}

The morphology of the fracture surfaces of RHDPE/EVA blends were studied by using scanning electron microscope model JEOL JSM-6460LA. Before the examination of SEM, the samples were mounted on aluminium stubs and allowed to undergo sputtering coating. A thin platinum layer of $20 \mathrm{~nm}$ was sputter coated on the samples surfaces to avoid electrostatic charged during examination.

\subsection{Fourier Transform Infrared (FTIR) Spectroscopy}

The FTIR spectra were obtained by using Perkin-Elmer Spectrum 400 Series equipment. The selected spectrum resolution and the scanning range were $4 \mathrm{~cm}^{-1}$ and $650-4000 \mathrm{~cm}^{-1}$, respectively. The FTIR spectra with percentage transmittance $(\% \mathrm{~T})$ versus wavelength $\left(\mathrm{cm}^{-1}\right)$ were gained after scanning process. 


\section{RESULTS AND DISCUSSION}

\subsection{Tensile Properties}

Figure 1 shows the effect of compatibilisers on tensile strength of RHDPE/EVA, RHDPE/EVA/PE-g-MAH, and RHDPE/EVA/CL-MAH blends. It can be seen that all blends significantly decreased in tensile strength with increasing content of EVA. This was due to the presence of EVA which influenced the crystalline structure of RHDPE due to EVA amorphous characteristic. Increase in EVA content obstructed the ordered arrangement of RHDPE and reduced their crystallinity, which in turn caused reduction in tensile strength value. ${ }^{13}$

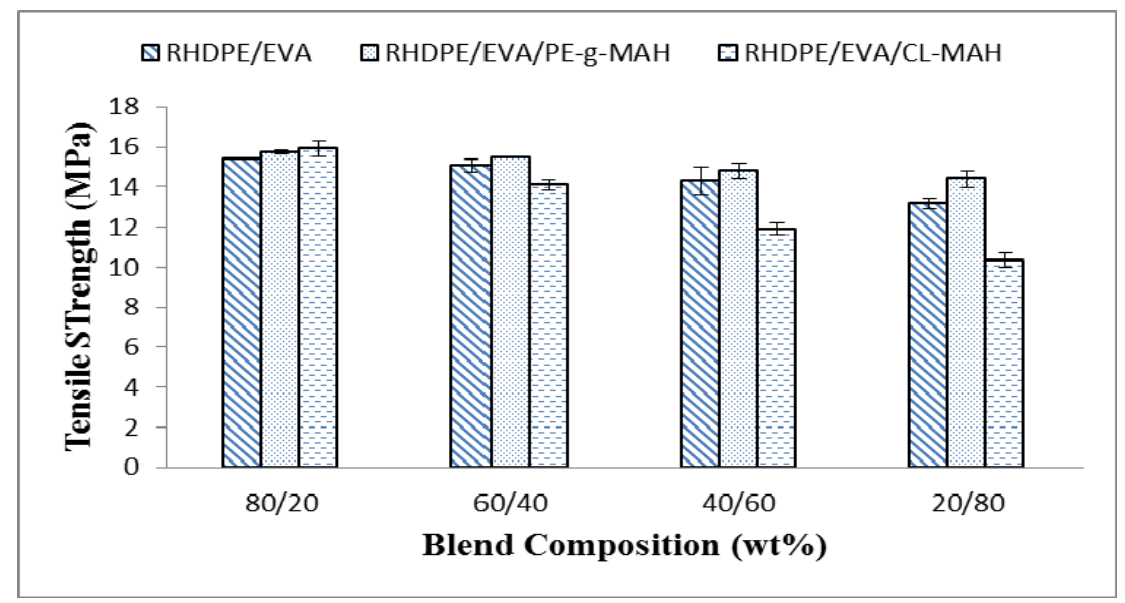

Figure 1: Effect of blend composition and compatibiliser on tensile strength of RHDPE/EVA, RHDPE/EVA/PE-g-MAH, and RHDPE/EVA/CL-MAH blends.

At the same blend composition, compatibilised blends with PE-g-MAH reveal higher tensile strength than uncompatibilised RHDPE/EVA blends. This can be explained by the improvement of interfacial adhesion as PE-g-MAH was added due to reaction of carbonyl group in PE-g-MAH to ester group of EVA, which would form covalent bonds, enhanced the improvement and efficiency of stress transfer from RHDPE to EVA matrix as presented in Figure 2. This was similar to the findings of several researches which agreed that with accumulation of compatibiliser to the blends will helped to increase the tensile strength of the blends. ${ }^{17-19}$ 


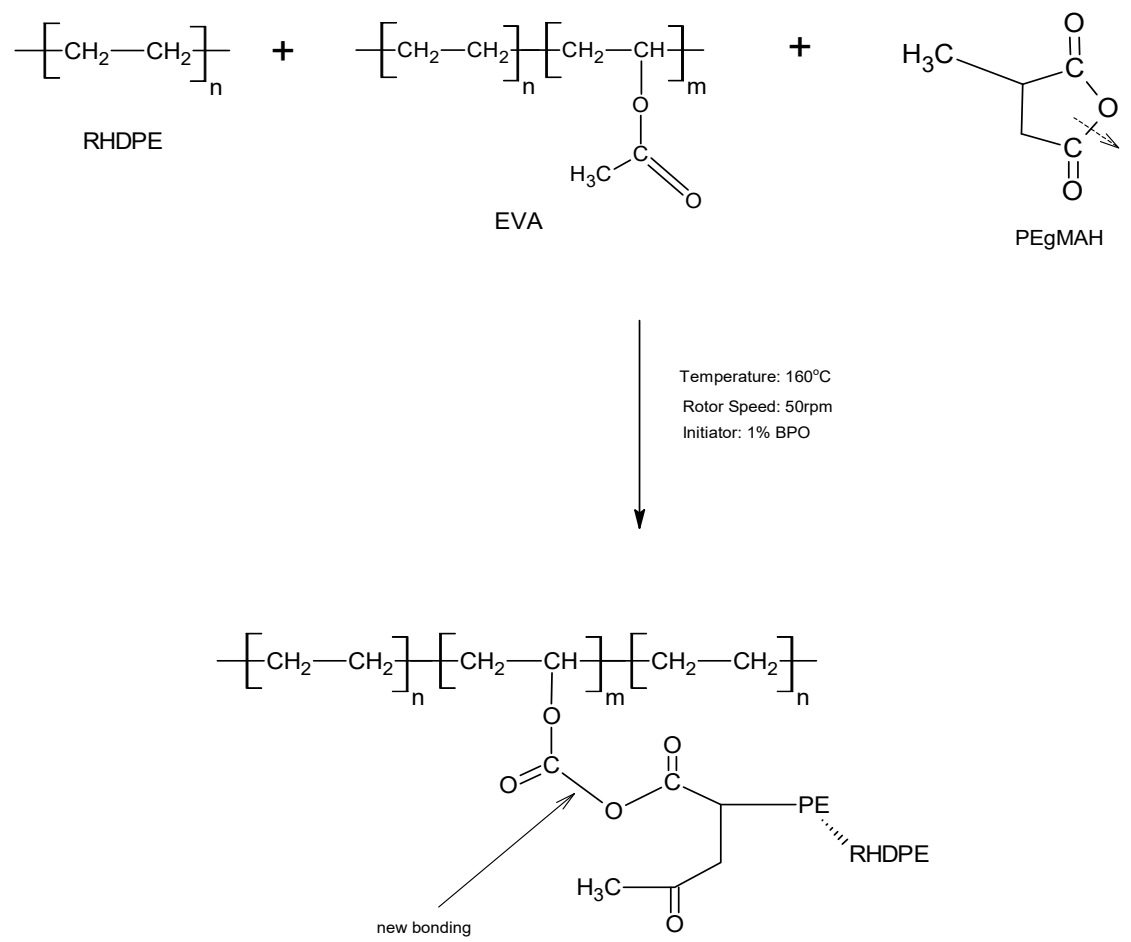

Figure 2: Illustration mechanism of interaction between PE-g-MAH and RHDPE/EVA blends.

Figure 1 also shows that the presence of CL-MAH in blend composition of RHDPE80/EVA20/CL-MAH displayed the highest in tensile strength, but showed decreasing trends in other blend compositions of RHDPE and EVA. Hybridisation of caprolactam with maleic anhydride created hydrogen bonding and dipole-dipole interaction between the two compatibilisers as illustrated in Figure 3. These bonding and interaction created reactive compatibiliser which can upgrade the improvement of interfacial adhesion of the blends. The reduction of interfacial adhesion size improved the miscibility of the two components as dispersed phase EVA blended well into RHDPE matrix. However, as the content of EVA increased, the tensile strength of RHDPE/EVA/CL-MAH blends significantly decreased due to reactive compatibilisers of caprolactam and maleic anhydride not compatible with increasing the content of EVA. Lack of adhesion between RHDPE and EVA resulted in EVA agglomerated in RHDPE matrix, which led to premature failure and reduced tensile strength. The reactive side of amine group in CL-MAH were more reactive to form bonding with RHDPE phases, therefore decreased in RHDPE content resulted in decrease of tensile strength. 


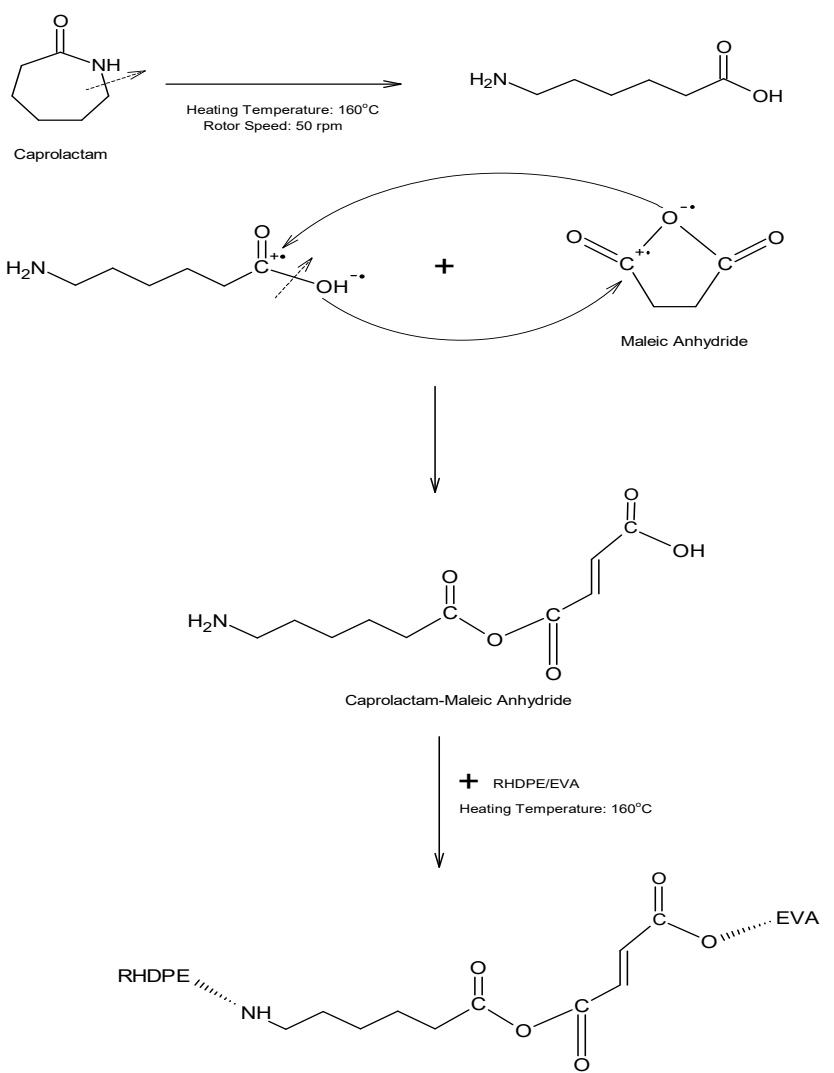

Figure 3: Illustration mechanism of interaction between caprolactam and maleic anhydride bonding to RHDPE/EVA blends.

Figure 4 presents the effect of different blend compositions and compatibilisers on elongation at break of RHDPE/EVA, RHDPE/EVA/PE-g-MAH, and RHDPE/EVA/CL-MAH blends. The elongation at break increased gradually with the increasing EVA loading. This was caused by the increase in the toughness of RHDPE/EVA blends due to higher elastic properties of EVA. Elasticity of EVA would somehow reduce the crystallinity properties of RHDPE, thus increasing elongation at break of the blends. Ismail et al. stated that by increasing the NBR content in PVCw/NBR blend will reduced the stiffness and brittleness of the blends gradually while increased the elongation at break. ${ }^{20}$ 


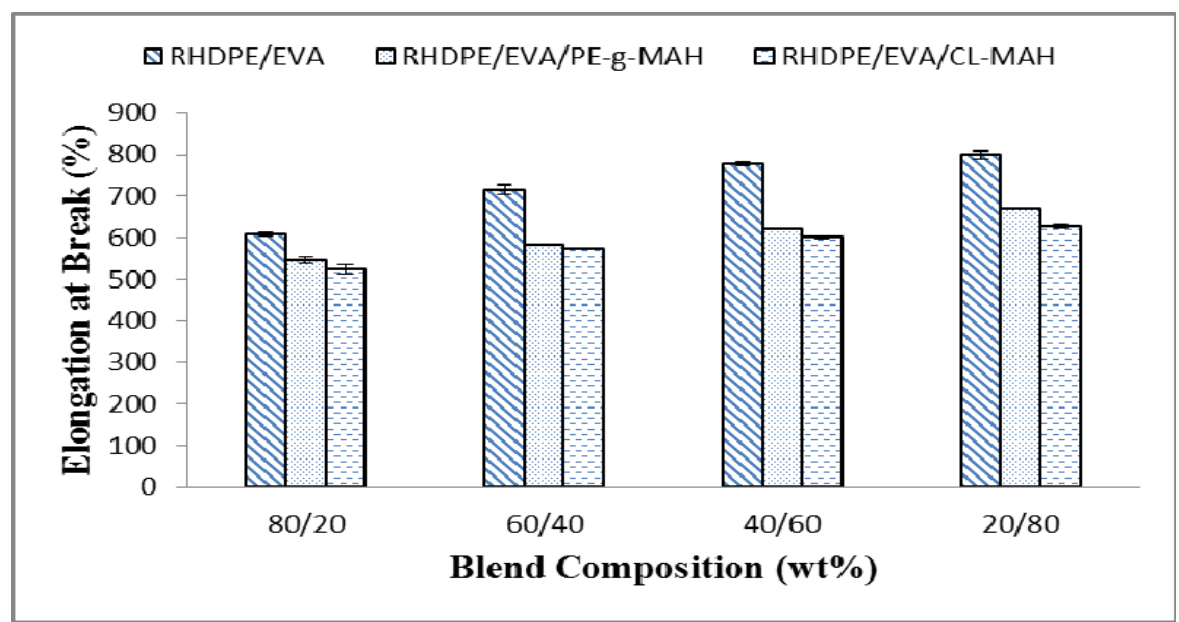

Figure 4: Effect of blend composition and compatibiliser on elongation at break of RHDPE/EVA, RHDPE/EVA/PE-g-MAH, and RHDPE/EVA/CL-MAH blends.

At similar blend composition, the elongation at break of RHDPE/EVA with both compatibilisers, PE-g-MAH and CL-MAH, was lower than the blends without compatibilisers. The addition of compatibiliser improved the adhesion at the interfaces of the matrixes and an increase in blend stiffness. However, it also caused a notable reduction in the elongation at break. Additionally, the addition of compatibiliser increased the interlocking between two phases, thus increasing the interfacial adhesion between phases in polymer state. This would lead to low mobility of the chains at RHDPE/EVA blend interface and reduced the elongation at break.

The effect of different blend compositions and compatibilisers on modulus of elasticity of RHDPE/EVA, RHDPE/EVA/PE-g-MAH, and RHDPE/EVA/CLMAH blends was shown in Figure 5. All of the sets presented a decreased trend as the composition of EVA increased. The decrease in the elasticity modulus for all the composites with increasing EVA content might be due to the elastic characteristic of EVA which exhibits rubber-like properties, thus increasing ductility of the composites. Moreover, decrease in stiffness and toughness of composites resulted in subsequent decrease in tensile modulus of the composites. Faker et al. had studied the effect of mechanical behaviour of PE/EVA blends. The results from particle size distribution measurements showed that PE-rich blends had better tensile properties than EVA-rich blends. The small and welldistributed particles led to improvement in compatibility and interfacial interaction. ${ }^{21}$ 


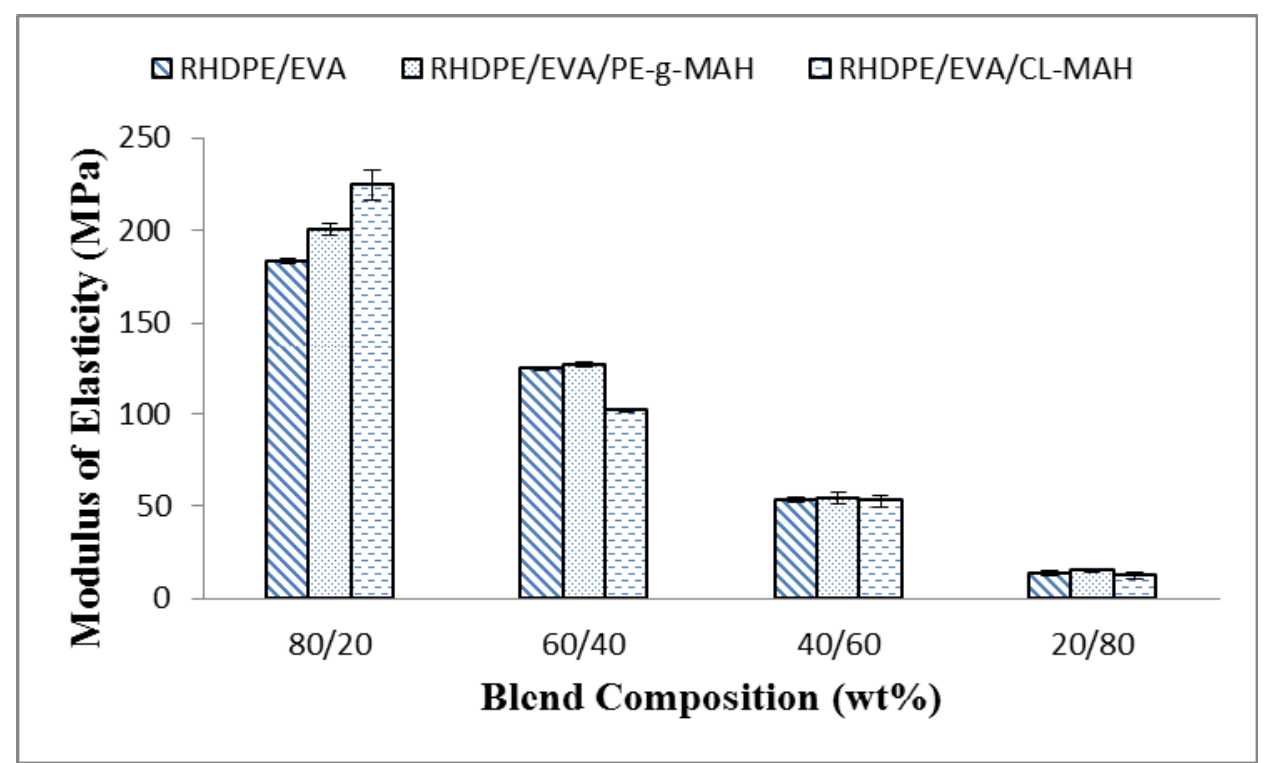

Figure 5: Effect of blend composition and compatibiliser on modulus of elasticity of RHDPE/EVA, RHDPE/EVA/PE-g-MAH, and RHDPE/EVA/CL-MAH blends.

The compatibilised blends with PE-g-MAH exhibited better elasticity modulus than RHDPE/EVA blends without presence of compatibiliser. The addition of PE-g-MAH to the RHDPE/EVA blends altered the surface of the blends and became coarse. The association of PE-g-MAH at the interface of two different matrixes resulted in lowered interfacial tension of the blends, therefore increasing the modulus values. ${ }^{3}$

However, from Figure 5, the addition of CL-MAH increased the modulus of elasticity just for the blend composition of RHDPE80/EVA20, while the rest of the blend composition showed decreasing modulus of elasticity with addition of CL-MAH. The reasoning behind this could be that the compatibilising effect was restricted merely to the amorphous part of EVA that would reduce the modulus value accordingly. These results also validated to the incompatibility of the blends with addition of CL-MAH corresponding to increase of EVA, which reduced the tensile properties of the blends. The softening effect of CL-MAH reacting with increasing EVA content attributed to the fact that the compatibiliser itself has lower modulus of elasticity. ${ }^{22}$ 


\subsection{Swelling Behaviour}

Figure 6 presents the percentage mass swell for RHDPE/EVA, RHDPE/EVA/PEg-MAH, and RHDPE/EVA/CL-MAH blends. The increasing EVA content significantly increased the percentage mass swell for all the blends. This can be described by the reactive reaction of EVA to dichloromethane. The polar group from EVA would react to intermediate polar of dichloromethane and kept on swelling for $46 \mathrm{~h}$ of the blends in dichloromethane.

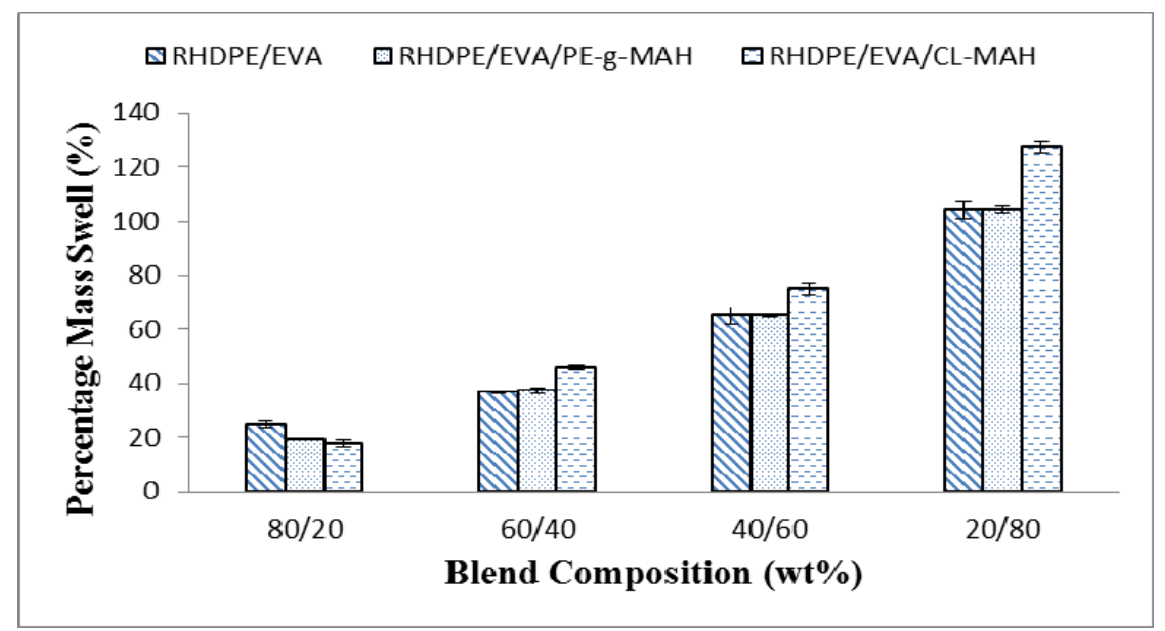

Figure 6: Effect of blend composition and compatibiliser on percentage mass swell of RHDPE/EVA, RHDPE/EVA/PE-g-MAH, and RHDPE/EVA/CL-MAH blends.

The percentage mass swell of RHDPE/EVA/PE-g-MAH blends was lower than RHDPE/EVA blends in similar blend composition. The better interfacial adhesion of the polymer blend due to addition of compatibiliser restricted the intake of dichloromethane into the blends. Hence, the solvent exhibited better swelling resistance. However, the addition of CL-MAH as compatibiliser increased the percentage mass swell for RHDPE/EVA/CL-MAH for 60/40, $40 / 60$, and 20/80 blends. CL-MAH, which is polar, formed in situ to the polar part of the EVA, resulting in higher absorption of dichloromethane and causing high percentage of mass swell for RHDPE/EVA/CL-MAH blends.

\subsection{Morphology Analysis}

SEM micrographs of the tensile fracture surfaced of RHDPE/EVA, RHDPE/EVA/PE-g-MAH, and RHDPE/EVA/CL-MAH are shown in Figure 7. Figure 7(a), 7(b) and 7(c), which represent the morphology of blends without 
addition of compatibiliser showed poor interfacial adhesion with many clear gaps and distinct cavities within the RHDPE and EVA phases. It can be seen in all these figures that as the EVA composition increased the nature of failure surface changes from the rough failure surfaces into smooth failure surfaces.

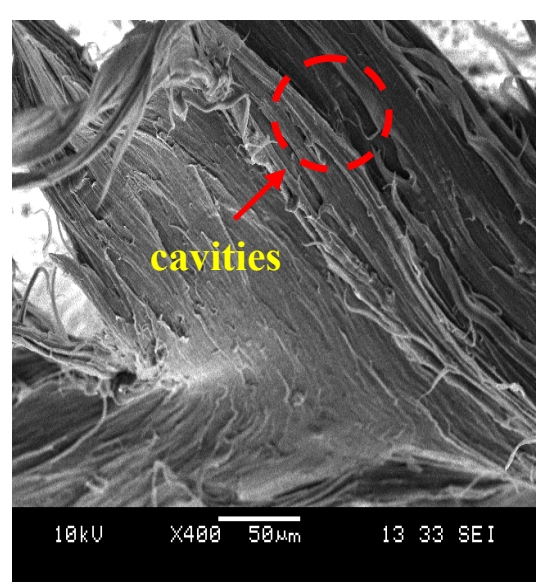

(a) RHDPE80/EVA20

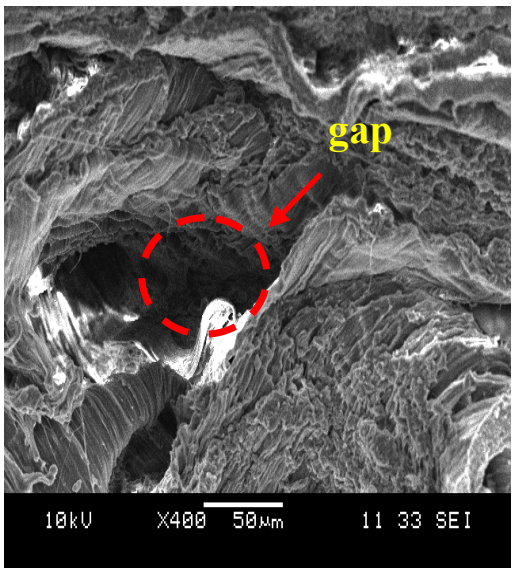

(b) RHDPE60/EVA40

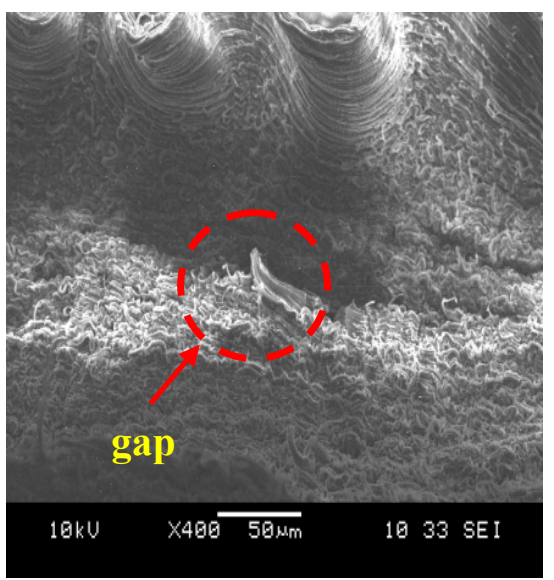

(c) RHDPE20/EVA80

Figure 7: SEM of tensile fractured surfaces of RHDPE/EVA blends.

At same composition, the addition of PE-g-MAH in RHDPE/EVA/PE-g-MAH blends was shown in Figure $8(\mathrm{a}-\mathrm{c})$. The blend compatibilisation was improved with the interfacing of two phases becoming more indistinct and less noticeable. Nevertheless, the presence of many tear lines indicated that strong interfacial adhesion between the polymers, thus higher strength would be needed to break the blends as proved with higher value of tensile strength in Figure 1. Akhlaghi et 
al. $^{23}$ had reported that by addition of PE-g-MAH as a compatibiliser in HDPE/EVA matrix decreased the interfacial tension between the major and minor phases, hence providing finer dispersion of minor phase in the matrix.

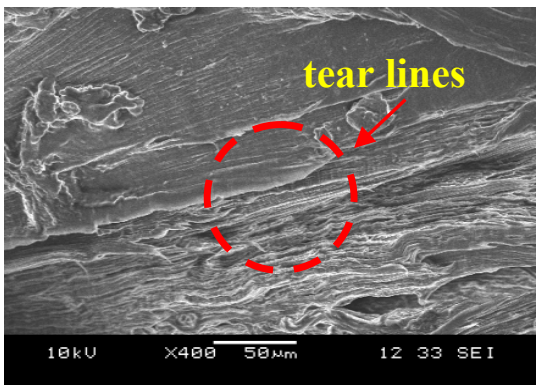

(a) RHDPE80/EVA20/PE-g-MAH

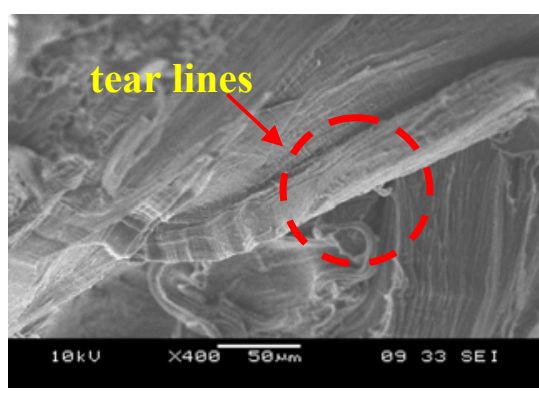

(b) RHDPE60/EVA40/PE-g-MAH

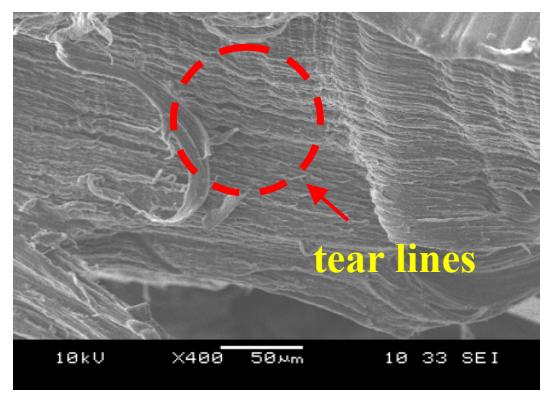

(c) RHDPE20/EVA80/PE-g-MAH

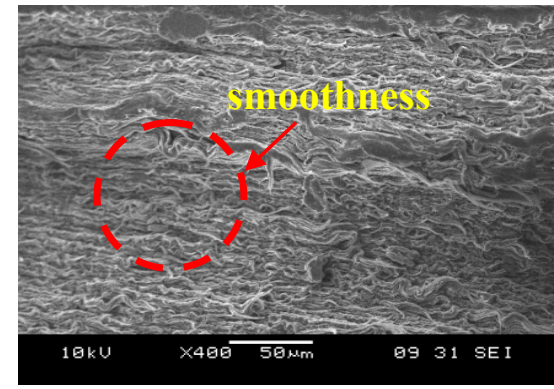

(d) RHDPE80/EVA20/CL-MAH

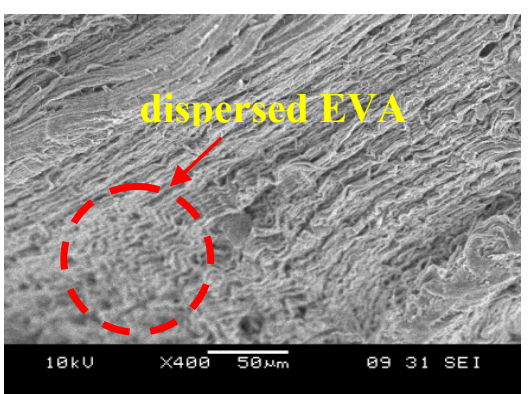

(e) RHDPE60/EVA40/CL-MAH

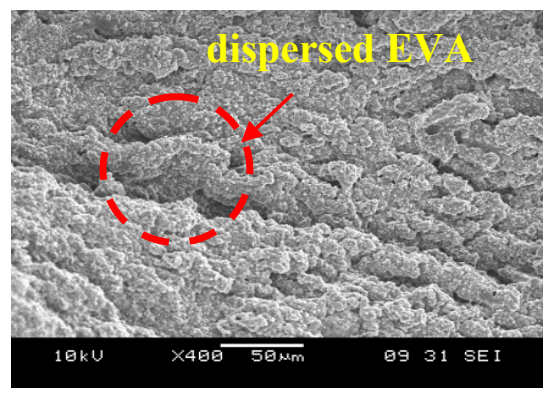

(f) RHDPE20/EVA80/CL-MAH

Figure 8: SEM of tensile fractured surfaces of RHDPE/EVA/PE-g-MAH and RHDPE/ EVA/CL-MAH blends.

Figure 8(d) to 8(f) display the SEM micrographs of tensile fracture surfaces of RHDPE/EVA/CL-MAH blends at different blend compositions. Figure 8 (d) shows that the EVA was finely and uniformly dispersed in the continuous RHDPE matrix with existence of CL-MAH. This suggested that a relatively 
higher efficiency of blend compatibilisation using CL-MAH consequently enhanced mechanical properties.

However, Figure $8(\mathrm{e}-\mathrm{f})$ clearly revealed that the smoothness in fracture surfaces with uneven distribution of the dispersed EVA phase and unstable particle structure may be caused by the reactive compatibiliser, which was not applicable to the blend composition of RHDPE60/EVA40 and RHDPE20/EVA80.

\subsection{Infrared Spectroscopy Analysis}

Figure 9 displays the FTIR spectra of RHDPE/EVA, RHDPE/EVA/PE-g-MAH, and RHDPE/EVA/CL-MAH blends. The sharp, strong stretching frequency from $2850 \mathrm{~cm}^{-1}$ to $3000 \mathrm{~cm}^{-1}$ exhibited $-\mathrm{CH}_{2}$ symmetric stretching. This was due to $\mathrm{sp}^{3} \mathrm{C}-\mathrm{H}$ stretching for ethylene groups from RHDPE and EVA matrixes. From the spectra, the peak at average $1740 \mathrm{~cm}^{-1}$ showed $\mathrm{C}=\mathrm{O}$ strong stretch ascribed to carbonyl group corresponding to ester bond within EVA. Besides that, RHDPE/EVA/CL-MAH blends, shown in Figure 9(c) unveiled a characteristic bending frequency at $1632.7 \mathrm{~cm}^{-1}$, conforming to $\mathrm{NH}_{2}$ medium to strong scissoring of amide group in Caprolactam of CL-MAH compatibiliser. The spectra revealed $-\mathrm{CH}_{2}$ bending deformation at range between $1462 \mathrm{~cm}^{-1}$ and 1464 $\mathrm{cm}^{-1}$. The ester vibration at peaks of $1239.6,1240.15$, and $1240.71 \mathrm{~cm}^{-1}$ exhibits $\mathrm{C}-\mathrm{O}-\mathrm{C}$ stretching. Moreover, all bands in the frequency range from 700 to 900 $\mathrm{cm}^{-1}$ for all spectra were assigned to $\mathrm{C}-\mathrm{H}$ out-of-plane bending vibrations.

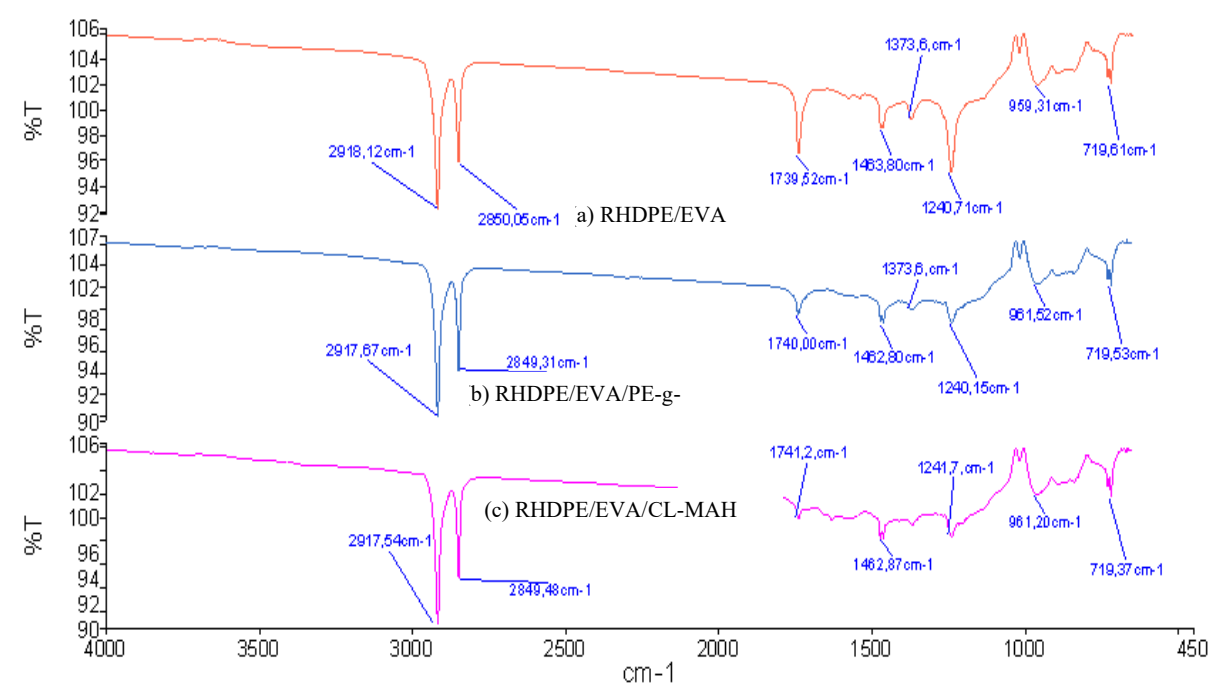

Figure 9: The FTIR spectra of: (a) RHDPE/EVA, (b) RHDPE/EVA/PE-g-MAH, and (c) RHDPE/EVA/CL-MAH blends. 


\section{CONCLUSION}

The addition of polyethylene-grafted-maleic anhydride and caprolactam-maleic anhydride as compatibilisers in the RHDPE/EVA blends increased the tensile strength and modulus of elasticity while reducing the elongation at break. The presence of PE-g-MAH and CL-MAH enhanced the interfacial adhesion between RHDPE/EVA phases, thus improving the compatibility of the RHDPE/EVA blends, as evidenced by morphological study using SEM. FTIR spectroscopy data also indicated that there was a bonding formation formed between the blend with the compatibilisers. Finally, based on the result obtained, the RHDPE/EVA blends can be applied and widely used in many applications such as bumper and car body in automotive application, multilayer packaging, and wire and cable coating in electrical application. The ratio blend of RHDPE80/EVA20 with addition of compatibiliser was the most optimum formulation due to the enhancement of properties proved by the testing results.

\section{REFERENCES}

1. Huang, J. et al. (2014). Study on the rheological, thermal and mechanical properties of thermoplastic polyurethane/poly (butylene terephthalate) blends. Polym. Test., 36, 69-74, DOI: 10.1016/j.polymertesting.2014. 03.006 .

2. Harper, C. A. (2002). Handbook of plastics, elastomers, and composites. London: McGraw-Hill.

3. Chevallier, C., Becquart, F. \& Taha, M. (2013). Polystyrene/ polycarbonate blends compatibilization: Morphology, rheological and mechanical properties. Mater. Chem. Phys., 139(2-3), 616-622, DOI: 10.1016/j.matchemphys.2013.02.006.

4. Kouini, B. \& Serier, A. (2012). Properties of polypropylene/polyamide nanocomposites prepared by melt processing with a PP-g-MAH compatibilizer. Mater. Des., 34: 313-318, DOI:10.1016/j.matdes. 2011. 08.025 .

5. Mark, J. E., Erman, B. \& Roland, M. (2013). The science and technology of rubber, vol. 4. Oxford: Academic Press.

6. Stary, Z. et al. (2012). Influence of a compatibilizer on the morphology development in polymer blends under elongation. Polym., 53, 18811889, DOI: 10.1016/j.polymer.2012.02.056.

7. Zhang, Q., Yang, H. \& Fu, Q. (2004). Kinetics-controlled compatibilization of immiscible polypropylene/polystyrene blends using nano- $\mathrm{SiO}_{2}$ particles. Polym., 45, 1913-1922, DOI: 10.1016/j.polymer. 2004.01.037. 
8. Argoud, A. et al. (2014). Morphologies in polyamide 6/high density polyethylene blends with high amounts of reactive compatibilizer. Eur. Polym. J., 50, 177-189, DOI: 10.1016/j.eurpolymj.2013.10.026.

9. Tseng, F. P. et al. (2001). Poly(oxypropylene)-amide grafted polypropylene as novel compatibilizer for PP and PA6 blends. Polym., 42(2), 713-725.

10. Zhang, H. et al. (2007). Structure and properties of compatibilized recycled poly(ethylene terephthalate)/linear low density polyethylene blends. Eur. Polym. J., 43(8), 3662-3670, DOI: 10.1016/ j.eurpolymj.2007.05.001.

11. Reis, J. M. L. et al. (2013). Influence of the temperature and strain rate on the tensile behavior of post-consumer recycled high-density polyethylene. Polym. Test., 32(8), 1576-1581, DOI: 10.1016/ j.polymertesting.2013.10.008.

12. Reis, J. M. L., Pacheco, L. J. \& da Costa Mattos, H. S. (2013). Tensile behavior of post-consumer recycled high-density polyethylene at different strain rates. Polym. Test., 32(2), 338-342, DOI: 10.1016/ j.polymertesting.2012.11.007.

13. Chen, Y. et al. (2014). Melting and crystallization behavior of partially miscible high density polyethylene/ethylene vinyl acetate copolymer (HDPE/EVA) blends. Thermochim. Acta, 586, 1-8, DOI: 10.1016/ j.tca.2014.04.007.

14. Bidsorkhi, H. C. et al. (2014). Mechanical, thermal and flammability properties of ethylene-vinyl acetate (EVA)/sepiolite nanocomposites. Polym. Test., 37, 117-122, DOI: 10.1016/j.polymertesting.2014.05.007.

15. Takidis, G. et al. (2003). Compatibility of low-density polyethylene/poly(ethylene-co-vinyl acetate) binary blends prepared by melt mixing. J. Appl. Poly. Sci., 90(3), 841-852, DOI: 10.1002/ app.12663.

16. Bing, N. et al. (2004). Orientation effects on the deformation and fracture properties of high-density polyethylene/ethylene vinyl acetate (HDPE/EVA) blends. Polym. Int., 53, 1078-1086, DOI: 10.1002/pi.1495.

17. Tseng, F. P. et al. (2001). Poly(oxypropylene)-amide grafted polypropylene as novel compatibilizer for PP and PA6 blends. Polym., 42(2), 713-725, DOI:10.1016/S0032-3861(00)00400-6.

18. Ma, H. \& Yang, Y. (2008). Rheology, morphology and mechanical properties of compatibilizedpoly(vinylidene fluoride) (PVDF)/ thermoplastic polyurethane (TPU) blends. Polym. Test., 27(4), 441-446, DOI: 10.1016/j.polymertesting.2008.01.009.

19. Shabbir, S. et al. (2013). Enhancement of thermal stability, processability and morphology of polystyrene blends. Thermochim. Acta, 573, 213219, DOI: 10.1016/j.tca.2013.09.016. 
20. Ismail, H., Supri \& Yusof, A. M. M. (2004). Blend of waste poly(vinylchloride) (PVCw)/acrylonitrile butadiene-rubber (NBR): The effect of maleic anhydride (MAH). Polym. Test., 23(6), 675-683, DOI: 10.1016/j.polymertesting.2004.01.008.

21. Faker, M. et al. (2008). Rheology, morphology and mechanical properties of polyethylene/ethylene vinyl acetate copolymer (PE/EVA) blends. Eur. Polym. J., 44(6), 1834-1842, DOI: 10.1016/j.eurpolymj. 2008.04.002.

22. Spencer, M. W. et al. (2010). Morphology and properties of nanocomposites based on HDPE/HDPE-g-MA blends. Polym., 51(5), 1056-1070, DOI: 10.1016/j.polymer.2009.12.047.

23. Akhlaghi, S. et al. (2012). Effect of stabilizer on the mechanical, morphological and thermal properties of compatibilized high density polyethylene/ethylene vinyl acetate copolymer/organoclay nanocomposites. Mater. Des., 33, 273-283, DOI: 10.1016/j.matdes.2011. 07.044 . 